
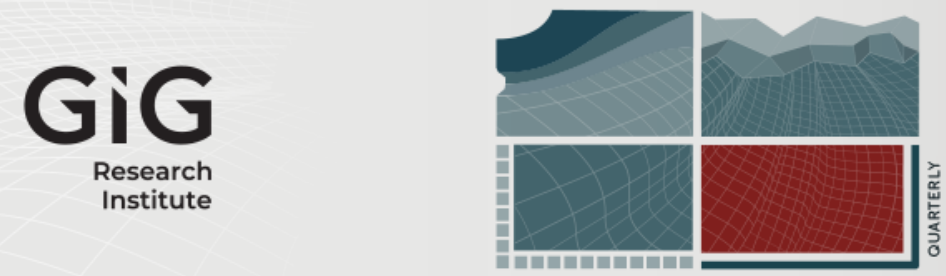

JOURNAL

OF

SUSTAINABLE

MINING

Volume 19 | Issue 1

Article 2

2020

\title{
Prospective study on safety climate of surface mining in Pakistan
}

Author(s) ORCID Identifier:

Izhar Mithal Jiskani (iD) 0000-0002-3220-8880

Saleem Raza Chalgri (iD) 0000-0002-6956-3579

Niaz Muhammad Shahani (iD) 0000-0002-3427-577X

Abdullah Rasheed Qureshi (iD) 0000-0002-7891-0683

Follow this and additional works at: https://jsm.gig.eu/journal-of-sustainable-mining

Part of the Explosives Engineering Commons, Oil, Gas, and Energy Commons, and the Sustainability

\section{Commons}

\section{Recommended Citation}

Jiskani, Izhar Mithal; Chalgri, Saleem Raza; Memon, Safiullah; Shahani, Niaz Muhammad; and Qureshi, Abdullah Rasheed (2020) "Prospective study on safety climate of surface mining in Pakistan," Journal of Sustainable Mining: Vol. 19 : Iss. 1 , Article 2.

Available at: https://doi.org/10.46873/2300-3960.1001

This Research Article is brought to you for free and open access by Journal of Sustainable Mining. It has been accepted for inclusion in Journal of Sustainable Mining by an authorized editor of Journal of Sustainable Mining. 


\title{
Prospective study on safety climate of surface mining in Pakistan
}

\begin{abstract}
The purpose of this study was to assess miners' perceptions about the safety climate of their workplace. To achieve the research aim, the relationship between demographic characteristics and occupational hazards was first determined, and finally, the relationship of safety climate with occupational hazards and health-seeking behavior was discovered. The data was collected through a self-reporting questionnaire. The results revealed that the subjects have to deal with severe occupational hazards, and they possess poor health-seeking behavior. A safety climate assessment showed that only one of the seven dimensions (i.e. safety communication, learning, and trust in co-worker safety competence) was at a satisfactory level. With respect to the first objective, we found that age, education, and experience were statistically significant with occupational hazards, while marital status had no significant impact on occupational hazards. Regarding the second objective, three dimensions (management safety justice, safety communication, learning, and trust in co-worker safety competence, and workers' trust in the efficacy of safety systems) were significant predictors of occupational hazards. The study reflects that workers' participation is the main factor in setting up an adequate safety climate within the organization. Suggestions provided in this study could provide useful information to managers and safety practitioners to improve safety performance and promote the safety climate in the organization.
\end{abstract}

\section{Keywords}

safety climate, occupational hazards, mineworkers, surface mining, mine health and safety

Creative Commons License

This work is licensed under a Creative Commons Attribution 4.0 License.

\section{Cover Page Footnote}

This study was supported by the Independent Research Project of State Key Laboratory of Coal Resources and Safe Mining, China University of Mining and Technology, Xuzhou, China (SKLCRSM18X001). The authors gratefully acknowledge the mining enterprises for facilitating data collection, and workers for their participation in this study.

\section{Authors}

Izhar Mithal Jiskani, Saleem Raza Chalgri, Safiullah Memon, Niaz Muhammad Shahani, and Abdullah Rasheed Qureshi 


\title{
Prospective study on safety climate of surface mining in Pakistan
}

\author{
Izhar Mithal Jiskani ${ }^{a, b, c, *}$, Saleem Raza Chalgri ${ }^{c}$, Safiullah Memon ${ }^{c}$, \\ Niaz Muhammad Shahani ${ }^{a}$, Abdullah Rasheed Qureshi ${ }^{\mathrm{d}}$, Zuhaib Aslam Jarwar ${ }^{\mathrm{c}}$ \\ ${ }^{a}$ School of Mines, China University of Mining and Technology, Xuzhou, China \\ b State Key Laboratory of Coal Resources and Safe Mining, China University of Mining and Technology, Xuzhou, China \\ ${ }^{\mathrm{c}}$ Department of Mining Engineering, Mehran University of Engineering and Technology, Jamshoro, Pakistan \\ ${ }^{\mathrm{d}}$ Department of Mining Engineering, Balochistan University of Information Technology, Engineering and Management Sciences, \\ Quetta, Pakistan
}

\begin{abstract}
The purpose of this study was to assess miners' perceptions about the safety climate of their workplace. To achieve the research aim, the relationship between demographic characteristics and occupational hazards was first determined, and finally, the relationship of safety climate with occupational hazards and health-seeking behavior was discovered. The data was collected through a self-reporting questionnaire. The results revealed that the subjects have to deal with severe occupational hazards, and they possess poor health-seeking behavior. A safety climate assessment showed that only one of the seven dimensions (i.e. safety communication, learning, and trust in co-worker safety competence) was at a satisfactory level. With respect to the first objective, we found that age, education, and experience were statistically significant with occupational hazards, while marital status had no significant impact on occupational hazards. Regarding the second objective, three dimensions (management safety justice, safety communication, learning, and trust in co-worker safety competence, and workers' trust in the efficacy of safety systems) were significant predictors of occupational hazards. The study reflects that workers' participation is the main factor in setting up an adequate safety climate within the organization. Suggestions provided in this study could provide useful information to managers and safety practitioners to improve safety performance and promote the safety climate in the organization.
\end{abstract}

Keywords: safety climate, occupational hazards, mineworkers, surface mining, mine health and safety

\section{Introduction}

$\mathrm{M}$ ining is one of the most dangerous industries in the world because it involves workers in dangerous conditions and exposes them to an increased risk of accidents. Pakistan's mining industry is subjected to many constraints, such as low socioeconomic status, lack of legislation, poor working conditions and lack of safety measures [1,2]. The industry is also not technologically advanced, so considerable attention should be paid for achieving sustainable economic growth through intelligent planning for the exploitation of indigenous mineral resources
[2-4]. Due to the unregulated nature of the mining industry, there is a long history of accidents and health complaints, which have not yet been resolved. Safety is a key component of sustainable mining practices, due to its implications for cost, delivery, quality, and social responsibility. Therefore, in order to maintain the sustainability of the mining industry, all mining activities must be carried out safely.

Hazardous environments and underestimation of safety risks are common problems in the industry, which can both lead to serious safety incidents. Poor health and safety practices, as well as mental stress and job insecurity, can also increase the risk of accidents $[5,6]$. In this context, the issue of workplace

Received 7 April 2019; revised 28 August 2019; accepted 9 December 2019.

Available online 5 October 2020

* Corresponding author.

E-mail address: imjiskani@hotmail.com (I.M. Jiskani). 
safety is highly relevant, as the risk of occupational hazards may have a negative impact on the future perceptions of safety climate [7]. Occupational health and safety management is an important aspect because it aims to adapt workers to their working environment in order to promote and maintain their well-being [8]. Compared with workers in other fields, mineworkers face relatively dangerous working environments [9]. In-depth investigations found that the safety awareness of mineworkers can be improved by reducing their unsafe behaviors [10].

Safety climate assessment is regarded as an emerging research field to address the demand for improvement in safety performance. In the 21st century, this field has dramatically developed and received more attention, and its research and practice have also achieved fruitful results [11]. Safety climate is the shared views on policies, procedures, and practices related to organizational safety. In short, a safety climate reflects employees' perception of the true value of organizational safety, which is a factor in reducing accidental injuries [12]. Researchers have developed many diagnostic tools to measure the status and progress of the safety climate within an organization. However, active monitoring of a variable that has proven to be a leading indicator of various safety outcomes remains a critical phase. Investigating and controlling the safety climate in the workplace plays an essential role in preventing accidents and improving the level of safety production. It can also significantly help enterprises identify hazards in the system and actively prevent the risks of accidents. Strengthening safety culture creates economic benefits, encourages employees to participate in safety management, and prevents mine accidents [13]. A study revealed that a low safety climate, in turn, impacts negatively on performance [14]. Research shows that management plays a vital role in shaping workers' behavior in the workplace. The perceived level of safety climate is related to the perceived mutual commitment between workers and their supervisors [15]. It can be said that enhancing safety in work has effectively reduced the number of workplace accidents. However, research also shows that many new occupational diseases are increasing year by year. For this, some countermeasures are also put forward to enhance the wellbeing of miners and reduce their unsafe behaviors [16]. Training, together with a strong safety culture, safety communication, and leadership skills, may help to produce the desired work safety behavior [17]. At present, technology and equipment can help create a safer working environment to achieve the goal of zero accidents in the workplace [18].

This study analyzed mineworkers' perceptions of the safety climate of the surface mining industry in Pakistan. Two objectives were set for this study: (a) to find a relationship between demographic characteristics and occupational hazards; (b) to discover whether there is any relationship between the safety climate, and occupational hazards and preventive health measures. In addition, the study will guide management to set up a favorable safety climate and provide workers with an opportunity to reflect their safety motivations and safety choices. This research contributes to the existing literature because there are few studies on the safety climate of the mining industry, especially in Pakistan.

\section{Methodology}

The safety climate was assessed through a crosssectional survey using a previously validated Nordic Safety Climate Questionnaire (NOSACQ-50), developed by [19]. The questionnaire consists of 50 items, divided into seven dimensions. These dimensions are shared perceptions of: management safety priority, commitment, and competence (D1); management safety empowerment (D2); management safety justice (D3); workers' safety commitment (D4); workers' safety priority and risk nonacceptance (D5); safety communication, learning, and trust in co-worker safety competence (D6); and workers' trust in the efficacy of safety systems (D7). This diagnostic tool was chosen because it allows more specific identification of areas of the organization that need improvements. It is based on the 4point Likert scale, which excludes neutral statements, which may have a negative impact on the outcome of the assessment. The questionnaire has both positively and negatively (reversed) formulated items.

Data from 108 male workers involved in surface mining operations who agreed to take part in the study was collected using the convenience sampling method. Most of the participants were illiterate and unable to fill out the questionnaire. Therefore, the questions were read and explained to them, and then the questionnaire was completed by one of the authors interviewing them. The anonymous survey consists of questions on demographic characteristics, occupational hazards, and preventive health measures. The participants were asked to rate the extent to which they considered an item to be a serious hazard. Responses for hazard seriousness 
Table 1. Demographic data of the participants.

\begin{tabular}{lll}
\hline Variable & Description & Frequency $(\%)$ \\
\hline Age (years) & $18-33$ & $38(35.2)$ \\
& $34-49$ & $37(34.3)$ \\
Marital status & $\geq 50$ & $33(30.6)$ \\
& Single & $24(22.2)$ \\
& Married & $82(75.9)$ \\
Education level & Other & $2(1.9)$ \\
& Uneducated & $56(51.9)$ \\
Total experience (years) & Primary & $38(35.2)$ \\
& Secondary & $14(13.0)$ \\
& $\leq 5$ & $37(34.3)$ \\
& $6-10$ & $51(47.2)$ \\
\hline
\end{tabular}

and the frequency with which it occurred, ranged from 1 - very low to 5 - very high.

The data from the questionnaire survey was coded in SPSS v23 by assigning corresponding values to various responses for analysis. The demographic characteristics, exposure to occupational hazards and preventive health measures were characterized using frequencies and percentages. The score of each dimension for NOSACQ-50 was analyzed and explained according to published guidelines. Pearson's Chi-square test at a 5\% significance level was used to discover the relationship between variables.

\section{Results}

The demographic data of the participants is presented in Table 1 . From all the survey respondents, $35.2 \%$ were between 18 and 33 years old, $75.9 \%$ were married, more than half of the participants (51.9\%) were uneducated, and $47.2 \%$ had $6-10$ years of work experience.

\subsection{Occupational hazards}

The results shown in Table 2 describes the extent to which participants perceived themselves exposed to occupational hazards. According to statistics, it can be assumed that the workplace was hazardous. This is clarified by $71.3 \%$ of participants who experienced pain/disorders in the body. The two most commonly reported hazards in this survey were the lifting and handling of heavy loads $(35.2 \%)$ and falling from height $(22.2 \%)$. Most participants, while on duty, were suffering from occupational diseases $(27.8 \%)$. Participants rated the severity level of harms and hazards as; minor $(38 \%)$, moderate $(25.9 \%)$ and serious $(36.1 \%)$. The presence of these hazards may not only pose a considerable threat to the health of the workers but may also affect the cost of the project.

Table 2. Participants' perception of occupational hazards.

\begin{tabular}{|c|c|c|c|c|c|}
\hline \multirow[t]{2}{*}{ Hazard } & \multicolumn{4}{|c|}{ Frequency $(\%)$} & \multirow[t]{2}{*}{ Mean (SD) } \\
\hline & $18-33$ & $34-49$ & $\geq 50$ & Total & \\
\hline Pain/disorder in body parts & $23(21.3)$ & $24(22.2)$ & $30(27.8)$ & $77(71.3)$ & $1.713(0.454)$ \\
\hline Fractures & $6(5.6)$ & $7(6.5)$ & $9(8.3)$ & $22(20.4)$ & $1.204(0.405)$ \\
\hline Occupational disease & $6(5.6)$ & $8(7.4)$ & $16(14.8)$ & $30(27.8)$ & $1.278(0.450)$ \\
\hline Struck by objects & $2(1.9)$ & $2(1.9)$ & $3(2.8)$ & $7(6.5)$ & $1.065(0.247)$ \\
\hline Lifting and handling heavy loads & $20(18.5)$ & $11(10.2)$ & $7(6.5)$ & $38(35.2)$ & $1.352(0.480)$ \\
\hline Falls from height & $9(8.3)$ & $6(5.6)$ & $9(8.3)$ & $24(22.2)$ & $1.222(0.418)$ \\
\hline Slips/trips & $4(3.7)$ & $7(6.5)$ & $6(5.6)$ & $17(15.7)$ & $1.157(0.366)$ \\
\hline Falling rock block & $1(0.9)$ & $9(8.3)$ & $4(3.7)$ & $14(13)$ & $1.130(0.337)$ \\
\hline Others & $2(1.9)$ & $2(1.9)$ & $4(3.7)$ & $8(7.4)$ & $1.074(0.263)$ \\
\hline Severity & & & & & $1.981(0.864)$ \\
\hline Minor & 19 (17.6) & $13(12)$ & $9(8.3)$ & $41(38)$ & \\
\hline Moderate & $9(8.3)$ & $10(9.3$ & $9(8.3)$ & $28(25.9)$ & \\
\hline Serious & $10(9.3)$ & $14(13)$ & 15 (13.9) & $39(36.1)$ & \\
\hline
\end{tabular}

Table 3. Responses to questions regarding preventive health measures.

\begin{tabular}{llllll}
\hline Item & \multicolumn{2}{l}{ Frequency $(\%)$} & & Mean (SD) \\
\cline { 2 - 5 } & $18-33$ & $34-49$ & $\geq 50+$ & Total \\
\hline Use of proper tools and machinery & $4(3.7)$ & $8(7.4)$ & $12(11.1)$ & $24(22.2)$ & $1.222(0.418)$ \\
Use of safety equipment & $3(2.8)$ & $2(1.9)$ & $8(7.4)$ & $13(12)$ & $1.120(0.327)$ \\
Safety and health trainings & $2(1.9)$ & $2(1.9)$ & $4(3.7)$ & $8(7.4)$ & $1.074(0.263)$ \\
Trained in first aid & $0(0)$ & $1(0.9)$ & $2(1.9)$ & $3(2.8)$ & $1.028(0.165)$ \\
Emergency services available & $2(1.9)$ & $1(0.9)$ & $3(2.8)$ & $6(5.6)$ & $1.056(0.230)$ \\
Sought treatment while injured & $0(0)$ & $0(0)$ & $3(2.8)$ & $3(2.8)$ & $1.028(0.165)$ \\
\hline
\end{tabular}




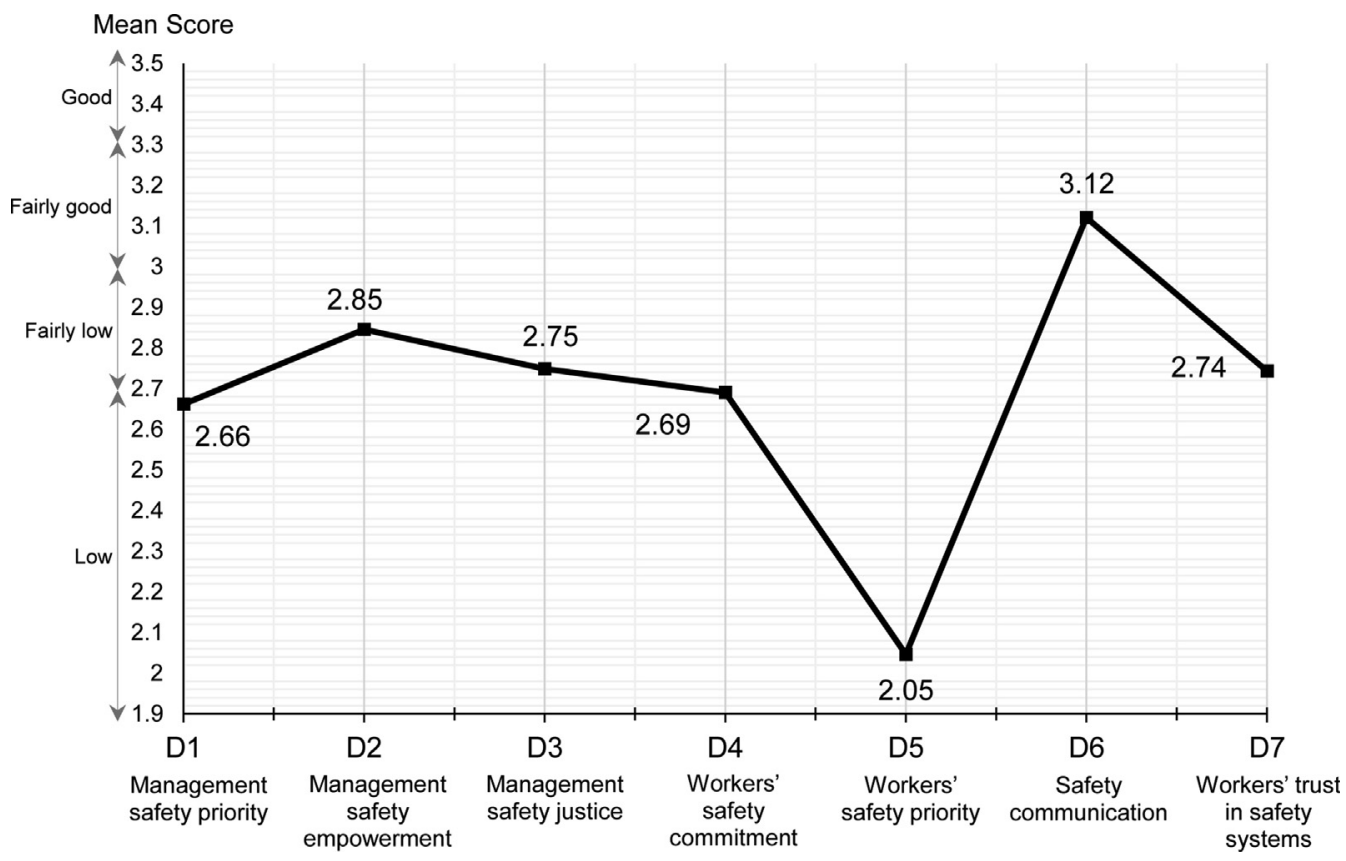

Fig. 1. Scores of seven dimensions of safety climate.

\subsection{Preventive health measures}

Participants' perceptions of preventive health measures are shown in Table 3 . The results indicate that the participants' perspective on the preventive health measure was low, and they had poor healthseeking behavior. A total of $77.8 \%$ of the participants were not using proper tools and equipment for their jobs, $88 \%$ were not provided with safety equipment, and $92.6 \%$ were not trained in health and safety precautions. Many participants (97.2\%) reported that they did not receive training in first aid methods and practices. Only $7.4 \%$ of the participants reported that they had received health and safety prevention training. Only $2.8 \%$ of the participants reported that they were trained to offer first aid in case of emergencies.

\subsection{Safety climate}

The results provided in Fig. 1 show scores of seven dimensions of safety climate. It gives an indication of how employees perceived and experienced safety in the workplace. There was only one dimension (safety communication, learning, and trust in co-worker safety competence) at an appropriate level, while three dimensions (management safety empowerment, management safety justice, and workers' trust in the efficacy of safety systems) were at a fairly satisfactory level of safety climate, which should be slightly improved. The remaining three dimensions (management safety priority, commitment, and competence, workers' safety commitment, and workers' safety priority and risk non-acceptance) were at a low level and required a great need for improvement. The

Table 4. The results of Pearson's chi-square test for the relationship between demographic characteristics and occupational hazards.

\begin{tabular}{lllll}
\hline Hazard & Age & Marital Status & Education & Experience \\
\hline Pain/disorder in body parts & $0.011^{*}$ & 0.579 & 0.139 & $0.000^{*}$ \\
Fractures & 0.47 & 0.524 & $0.004^{*}$ & 0.002 \\
Occupational diseases & $0.005^{*}$ & 0.351 & $0.049^{*}$ & $0.047^{*}$ \\
Struck by objects & 0.766 & 0.863 & $0.000^{*}$ & $0.024^{*}$ \\
Lifting and handling heavy loads & $0.015^{*}$ & 0.124 & 0.144 & $0.000^{*}$ \\
Falls from height & 0.52 & 0.726 & $0.009^{*}$ & 0.082 \\
Slips/trips & 0.546 & $0.000^{*}$ & 0.056 & 0.579 \\
Falling material & $0.020^{*}$ & 0.729 & $0.001^{*}$ & 0.214 \\
Other & 0.463 & 0.712 & 0.258 & 0.666 \\
Severity & 0.346 & 0.643 & $0.000^{*}$ & $0.030^{*}$ \\
\hline
\end{tabular}

*Significant at $\mathrm{p}<0.05$. 
Table 5. Association between study variables and safety climate using Pearson's chi-square test.

\begin{tabular}{lll}
\hline Dimension & Occupational hazard & Preventive health measure \\
\hline Management safety priority, commitment, and competence & 0.992 & 0.063 \\
Management safety empowerment & 0.767 & $0.002^{*}$ \\
Management safety justice & 0.000 & 0.151 \\
Workers' safety commitment & 0.397 & 0.248 \\
Workers' safety priority and risk non-acceptance & 0.499 & 0.075 \\
Safety communication, learning, and trust in co-worker safety competence & $0.019^{*}$ & $0.002^{*}$ \\
Workers' trust in the efficacy of safety systems & $0.000^{*}$ & 0.383 \\
\hline
\end{tabular}

*Significant at $\mathrm{p}<0.05$.

dimension with the highest value was safety communication, learning, and trust in co-worker safety competence (3.12), while the dimension with the lowest value was workers' safety priority and risk nonacceptance (2.05). From the results, the general level of safety climate can be considered as low, because the average scores of dimensions were between 2.05 and 3.12 and, therefore, are negative results. These pilot study findings indicate that it is necessary to strengthen the safety policy to improve the safety climate in the industry. An interesting finding was that $34.3 \%$ of this convenience sample had less than six years of experience, which could have an impact on their understanding of safety and, therefore, could affect the safety climate. These findings are not generalizable due to sample limitations. However, the results indicate that there is a problem that requires further investigation across the sector in Pakistan.

\subsection{Relationship between demographic characteristics and occupational hazards}

Table 4 presents the results of Pearson's Chisquare test for the relationship between demographic characteristics and occupational hazards. It was found that age is strongly associated with the hazards of pain/disorder in body parts, occupational diseases, lifting and handling loads, and falling material. Education was another significant factor related to occupational hazards concerning fractures, occupational diseases, being struck by objects, falling from height, and falling material. Whereas, lack of experience was a significant factor when it comes to pain/disorder in body parts, fractures, occupational diseases, struck by objects, lifting and handling heavy loads and the severity of the hazards. In prior studies, it was reported that age and experience could also impact occupational health and safety outcomes [20,21]. However, results did not show any other significant relationships between marital status and occupational hazards, only hazards caused by slips/trips were found to be significant. In general, older workers are more experienced and familiar with working conditions, but this also means that their role involves more responsibilities and risks. They may experience agerelated physical and psychological changes that affect their performance and expose them to potential harm $[22,23]$.

\subsection{Relationship between safety climate and study variables}

Table 5 shows the statistical results of the relationship between safety climate, occupational hazards, and health-seeking behavior. These results show a positive correlation. It was discovered that occupational hazards were significant with three dimensions of the safety climate, namely management safety justice, safety communication, learning, and trust in co-worker safety competence, and workers' trust in the efficacy of safety systems. The preventive health measures of participants were found to be significant for only two dimensions, i.e. management safety empowerment, and safety communication, learning, and trust in co-worker safety competence. These results lead to an important conclusion about the relationships that the presence of workplace hazard affects the overall safety climate. It suggests that these issues require immediate managerial intervention.

\section{Discussion}

This descriptive study was conducted to assess mineworkers' perceptions of the safety climate within the surface mining industry in Pakistan. A survey method was adopted to investigate the various aspects of safety in surface mining. The research framework adopted in this study found to be valuable for assessing workers' perceptions of safety climate. The results suggest that the nature of the job and the workload of a worker are among the key issues to address safety in the mining sector, but education and safety awareness also have a significant impact. Previous research has shown that job tenure is associated with greater job performance because, over time, workers gain more tacit 
knowledge and can more effectively perform their jobs [24-26]. The analysis of occupational health and safety hazards experienced by workers shows that these hazards may pose risks for injury or illness or may cause accidents. These accidents and injuries caused by these hazards can also have a predictive effect on safety climate [27]. The most frequently reported hazard by participants was pain/disorder in the body, referred to as musculoskeletal symptoms. In the U.S. logging industry, workers with musculoskeletal symptoms were more likely to have low safety priorities and accept risks in the workplace, which results in a low safety climate [28]. The other hazards involved in work were specified as the lifting and handling of heavy loads, falling from height, and occupational diseases. Manual material handling and fall prevention should be a major priority in order to alleviate the suffering of the individual worker, and industrial losses [29]. The analysis of participants' perspectives on the preventive health measure was low, and they had poor health-seeking behavior. They were not provided with the proper tools and equipment for their job and safety equipment. Most of them were not trained in health and safety precautions. These findings support the view that an employee's safety compliance and participation can be achieved through a positive safety climate. Specialized behavior-based training is an important tool that changes the behavior of mineworkers towards safety climate [30-32]. The analysis of safety climate shows that safety communication, learning, and trust in co-worker safety competence was the only dimension at an appropriate level. Whereas, management safety empowerment, management safety justice and workers' trust in the efficacy of safety systems were at a satisfactory level. However, workers also perceived three dimensions to be low, namely, management safety priority, commitment, and competence, workers' safety commitment, and workers' safety priority and risk nonacceptance. According to the average results of seven dimensions of safety climate, it can be said that the surface mining industry possesses a low safety climate. It is, however, important to remember that the current study is not based on a representative sample. From our survey, $34.3 \%$ of the participants had less than six years of experience in mining; one hypothesis could be that they may have no or less experience of other safety cultures and safety climates. The findings showed that age, education, and experience were statistically significant with regard to most hazards. In prior research, it was reported that age and experience could also affect occupational health and safety outcomes. The performance of experienced workers can be affected by their long exposure to potential harms [22,23]. The results of the relationship between safety climate, occupational hazards and health-seeking behavior show a positive correlation. The analysis showed the relationship of occupational hazards with management safety justice, safety communication, learning, and trust in co-worker safety competence and workers' trust in the efficacy of safety systems. While the relationship between preventive health measure, management safety empowerment and safety communication, learning, and trust in co-worker safety competence were also found in this study. Management commitment and attitude is an important dimension of workers' perception [33]. In recent years, it has become accepted that factors contributing to occupational health and safety incidents are related to the organizational risk management practices that are in place within the work environment [34]. [35] determined that the probability of incident reoccurrence is substantial after one's first injury. They suggested that more effective prevention measures should be put in place on a routine basis. Improving the safety climate, which focuses on commitment, involvement, and accountability can have a substantial impact on improving employee safety and reducing the frequency of the hazard occurrence as well as improving the viability of the organization. The presence of workplace hazards affects the overall safety climate. The findings from our study support one of the previous studies that states that job hazard has a direct impact on work injury [32]. This shows that these issues require immediate managerial intervention.

\section{Conclusions}

The participants' perception of workplace safety was illustrated through a cross-sectional survey aimed at determining the current level of safety climate. The results revealed that participants deal with severe occupational hazards, and they possess poor health-seeking behavior. The results of this study show that workers' perception of the safety climate of their workplace is very low. Therefore, it is necessary to formulate innovative approaches to reduce the risk of accidents, while at the same time ensure sustainable mining. This study provides some notable implications for workplace safety management in occupational health and safety issues to prioritize safety within the workplace. First, the mining sector needs effective management to improve safety within the organization. Authorities should ensure that both employers and employees comply with health and safety regulations and treat occupational health and safety issues as a collective 
responsibility to make the work environment safer. Management should put in place a mandatory safety program consisting of an integrated approach of education, enforcement, and engineering controls. The workforce should be provided with adequate protective tools, aid equipment, reasonable working conditions, and a clean and healthy work environment. It should be ensured that mining activities are updated and that work conforms to laws and regulations to improve human and environmental safety. Secondly, management and workers should consider safety to be a collaborative responsibility to improve working conditions. The outcomes of this study could be useful when applying resources and focusing on the appropriate areas in order to make safety improvements in the workplace.

\section{Conflicts of interest}

None declared.

\section{Ethical statement}

The authors state that the research was conducted according to ethical standards.

\section{Funding body}

This study was supported by the Independent Research Project of State Key Laboratory of Coal Resources and Safe Mining, China University of Mining and Technology, Xuzhou, China (SKLCRSM18X001).

\section{Acknowledgments}

The authors gratefully acknowledge the mining enterprises for facilitating data collection, and workers for their participation in this study.

\section{References}

[1] Jiskani IM, Wei Z, Chalgri SR, Qingxiang C, Behrani P, Aziz R. Prevalence of musculoskeletal disorders and assessment of workplace factors: A case of coal mine in Pakistan. In: Paper presented at the Thirty-Fifth Annual International Pittsburgh Coal Conference, Xuzhou, China; 2018.

[2] Jiskani IM, Ullah B, Shah KS, Bacha S, Shahani NM, Ali M, et al. Overcoming mine safety crisis in Pakistan: An appraisal. Process Saf Prog 2019;38(4):e12041. https://doi.org/ 10.1002/prs.12041.

[3] Jiskani IM, Siddiqui FI. Fault orientation modeling of sondajherruck coalfield, Pakistan. J Min Environ 2019;10(2):305-13. https://doi.org/10.22044/jme.2019.7415.1597.

[4] Jiskani IM, Siddiqui FI, Pathan AG. Integrated 3d geological modeling of sonda-jherruck coal field, Pakistan. J Sustain
Min 2018;17(3):111-9. j.jsm.2018.06.001.

[5] Beus JM, McCord MA, Zohar D. Workplace safety: A review and research synthesis. Organ Psychol Rev 2016;6(4):352-81.

[6] Laurence D. Establishing a sustainable mining operation: An overview. J Clean Prod 2011;19(2):278-84.

[7] Brown KA, Willis PG, Prussia GE. Predicting Safe employee behavior in the steel industry: Development and test of a sociotechnical model. J Oper Manag 2000;18(4):445-65.

[8] Armstrong M, Taylor S. Armstrong's handbook of human resource management practice. Kogan Page Publishers; 2014.

[9] Lenné MG, Salmon PM, Liu CC, Trotter M. A systems approach to accident causation in mining: An application of the hfacs method. Accid Anal Prev 2012;48:111-7.

[10] Cao Q, Yu K, Zhou L, Wang L, Li C. In-depth research on qualitative simulation of coal miners' group safety behaviors. Saf Sci 2019;113:210-32.

[11] Wang B, Wu C. Safety culture development, research, and implementation in China: An overview. Prog Nucl Energy 2019;110:289-300.

[12] Neal A, Griffin MA. Safety climate and safety behaviour. Aust J Manag 2002;27(2):S67.

[13] Lavaysse LM, Probst TM. Safety climate and safety outcomes: A meta-analytic comparison of universal vs. Industry-specific safety climate predictive validity $\mathrm{Au}$ - jiang, lixin. Work Stress 2019;33(1):41-57.

[14] Pandit B, Albert A, Patil Y, Al-Bayati AJ. Impact of safety climate on hazard recognition and safety risk perception. Saf Sci 2019;113:44-53.

[15] Newaz MT, Davis P, Jefferies M, Pillay M. The psychological contract: A missing link between safety climate and safety behaviour on construction sites. Saf Sci 2019;112:9-17.

[16] Li J-Z, Zhang Y-P, Wang X-J, Feng G-R, Zhang B-S, Wang T$R$, et al. Relationship research between subjective well-being and unsafe behavior of coal miners. Eurasia J Math Sci Technol Educ 2017;13(11):7215-21.

[17] Lehmann CC, Haight JM, Michael JH. Effects of safety training on risk tolerance: An examination of male workers in the surface mining industry. J SH\&E Res 2009;4(3):1-22.

[18] $\mathrm{Wu} \mathrm{D}, \mathrm{Li} \mathrm{Z}$. Work safety success theory based on dynamic safety entropy model. Saf Sci 2019;113:438-44.

[19] Kines P, Lappalainen J, Mikkelsen KL, Olsen E, Pousette A, Tharaldsen J, et al. Nordic safety climate questionnaire (Nosacq-50): A new tool for diagnosing occupational safety climate. Int J Ind Ergon 2011;41(6):634-46.

[20] Dragano N, Lunau T, Eikemo TA, Toch-Marquardt M, van der Wel KA, Bambra C. Who knows the risk? A multilevel study of systematic variations in work-related safety knowledge in the European workforce. Occup Environ Med 2015; 72(8):553. https://doi.org/10.1136/oemed-2014-102402.

[21] Dragano N, Barbaranelli C, Reuter M, Wahrendorf $M$, Wright B, Ronchetti M, et al. Young workers' access to and awareness of occupational safety and health services: Agedifferences and possible drivers in a large survey of employees in Italy. Int J Environ Res Public Health 2018;15(7): 1511. https://doi.org/10.3390/ijerph15071511.

[22] Parker AW, Tones MJ, Ritchie GE. Development of a multilevel health and safety climate survey tool within a mining setting. J Saf Res 2017;62:173-80.

[23] Paul PS, Maiti J. The role of behavioral factors on safety management in underground mines. Saf Sci 2007;45(4): 449-71.

[24] Breslin FC, Smith P. Age-related differences in work injuries: A multivariate, population-based study. Am J Ind Med 2005; 48(1):50-6.

[25] Haas EJ, Eiter B, Hoebbel C, Ryan ME. The impact of job, site, and industry experience on worker health and safety. Safety 2019;5(1):16.

[26] Schmidt FL, Hunter JE, Outerbridge AN. Impact of job experience and ability on job knowledge, work sample 
performance, and supervisory ratings of job performance. J Appl Psychol 1986;71(3):432-9.

[27] Beus JM, Payne SC, Bergman ME, Arthur Jr W. Safety climate and injuries: An examination of theoretical and empirical relationships. J Appl Psychol 2010;95(4):713-27.

[28] Lagerstrom E, Rosecrance J. The association between safety climate and musculoskeletal symptoms in the U.S. Logging industry. In: Paper presented at the 20th Congress of the International Ergonomics Association (IEA 2018), Cham; 2019.

[29] Leamon TB, Murphy PL. Occupational slips and falls: More than a trivial problem. Ergonomics 1995;38(3):487-98. https://doi.org/10.1080/00140139508925120.

[30] Clarke S. The relationship between safety climate and safety performance: A meta-analytic review. J Occup Health Psychol 2006;11(4):315.
[31] Lu C-S, Yang C-S. Safety climate and safety behavior in the passenger ferry context. Accid Anal Prev 2011;43(1):329-41.

[32] Maiti J, Chatterjee S, Bangdiwala SI. Determinants of work injuries in mines - an application of structural equation modelling. Inj Contr Saf Promot 2004;11(1):29-37. https:// doi.org/10.1076/icsp.11.1.29.26305.

[33] Zohar D. Safety climate in industrial organizations: Theoretical and applied implications. J Appl Psychol 1980;65(1): 96-102.

[34] García-Herrero S, Mariscal MA, García-Rodríguez J, Ritzel DO. Working conditions, psychological/physical symptoms and occupational accidents. Bayesian network models. Saf Sci 2012;50(9):1760-74.

[35] Pietilä J, Räsänen T, Reiman A, Ratilainen H, Helander E. Characteristics and determinants of recurrent occupational accidents. Saf Sci 2018;108:269-77. 